\title{
A Comparative Analysis of Linear and Nonlinear Control of Wave Energy Converter for a Force Control Application
}

\author{
A. Parwal, M. Fregelius, P.M. Almeida, O. Svensson, I. Temiz, J. G. Oliveira, C. Boström, and M. Leijon
}

\begin{abstract}
The aim of wave energy converters (WECs) is to harvest the energy from the ocean waves and convert into electricity. Optimizing the generator output is a vital point of research. A WEC behaves as a nonlinear system in real ocean waves and a control that approximates the behaviour of the system is required. In order to predict the behaviour of WEC, a controller is implemented with an aim to track the referenced trajectory for a force control application of the WEC. A neural model is implemented for the system identification and control of the nonlinear process with a neural nonlinear autoregressive moving average exogenous (NARMAX) model. The neural model updates the weights to reduce the error by using the Levenberg-Marquardt back-propagation algorithm for a single-input-single-output (SISO) nonlinear system. The performance of the system under the proposed scheme is compared to the same system under a PI-controller scheme, where the PI gains have been tuned accordingly, to verify the control capacity of the proposed controller. The results show a good tracking of $d q$ (direct-quadrature) axes currents by regulating the stator currents, and hence a force control is achieved at different positions of the translator. The dynamic performance of the control is verified in a time domain analysis for the displacement of the translator.
\end{abstract}

Keywords-current control, force control, neural NARMAX, permanent magnet linear generator (PMLG), wave energy converter.

Manuscript received 5 February 2019; revised 19 May 2020, accepted 25 June; published 26 June, 2020. This is an open access article distributed under the terms of the Creative Commons Attribution 4.0 licence (CC BY

http://creativecommons.org/licenses/by/4.0/). This article has been subject to single-blind peer review by a minimum of two reviewers. This work was supported by Swedish Research Council (VR) grant No. 2015-03126, the STandUP for Energy, and Erasmus Mundus (EMINTE) PhD Scholarship.

A. Parwal, M. Fregelius, O. Svensson, I. Temiz and C. Boström are with Division of Electricity, Department of Engineering Sciences, Uppsala University, Box 534, 75121 Uppsala, Sweden.

(e-mail: arvind.parwal@angstrom.uu.se).

P. M. Almeida and J. G. Oliveira are with Department of Electrical Energy, Universidade Federal de Juiz de Fora, Brazil.

M. Leijon is the Professor at Division of Electricity, Department of Engineering Sciences, Uppsala University, Box 534, 75121 Uppsala, Sweden and Department of Electrical Engineering, Chalmers University of Technology, 41296 Gothenburg, Sweden.

\section{INTRODUCTION}

$\mathrm{T}$ ODAY the concern about climate change and the increasing demand for energy makes the demand for renewable energy production considerable. Among renewable energy sources, wave power is gaining increased attention as ocean waves present an untapped renewable energy source of high energy density in [1]. Over the years, many efforts have been made to harvest this energy through different kinds of WECs [2]. A review of the most prominent technologies is found in [3]-[26]. The device and the data analysis methods are discussed and presented with results for controlling the mooring loads in [3]. A series of 1:25 scale model is experimentally and numerically compared in [4]. A wave-to-wire modelling of wave energy arrays for off-grid systems using low power permanent magnet linear generators is presented in [7]. The numerical modelling of the oscillating water column (OWC) wave energy converter (WEC) integrated into vertical breakwaters is presented in [15]. The development and testing of a novel pumped hydro storage concept for storing large amounts of electrical energy offshore is presented in [24]. The power take-off (PTO) components are presented with a novel wave energy device called "Symphony Wave Power" in [9]. Innovative microgrid solution for renewable energy integration is proposed in [11]. Leijon et al. [13] presented the development of the Swedish wave energy research area located close to Lysekil on the Swedish west coast. A description of the WEC is shown as in Fig. 1. A case study of 20 wave energy converters is used to illustrate the results to investigate the impact of grid-connected farm in [16]. A critical review is presented for a wave energy utilization in [19]. There are various ways of categorizing the types of WEC devices, as first described by Hagerman [27]. These can be categorized into three popular methods of absorbing the energy: the overtopping device, the oscillating water column, and the oscillating body. The latter can be further divided into three sub-categories, based on the direction of the radiation force. These are the attenuators, the terminators, and the point absorbers. The point absorber is defined as having a device-width significantly smaller than the wavelength of the incoming waves. The PTO unit may be hydraulic, pneumatic or 
electric, and the PTO can either be floating, submerged or installed on the seabed. Among these topologies, heaving point absorbers (HPAs) are perhaps the simplest in terms of overall architecture, besides having the ability to directly convert absorbed energy into electricity [28].

The energy absorption of a WEC in regular and irregular waves can be influenced by a declutching control in [29]. A study about constrained and unconstrained optimal control of a heaving pointabsorber was investigated in [30]. A real-time control to a point-absorber by adjusting the PTO damping was studied in [31]. Since the input to the controller is fluctuating in irregular waves, linear PI (proportionalintegral) controllers may not provide the optimal solution for the output regulation. In reality, most of the systems are nonlinear and require a suitable controller designing. However, it has been found that the tuned controller (e.g. PI-controller) may not be suitable to achieve the desired performance [32], [33]. Therefore, a nonlinear model which can capture the nonlinear behaviour and system characteristics over the wide range of processes is required for a stable and desired regulation. Several advanced strategies such as sliding mode control, adaptive multi-model sliding have been proposed in [34]-[36] to control nonlinear systems. Today, the nonlinear systems are well known for their complexity and dynamic behaviour.

\section{A. Related work}

Artificial neural networks (ANN) is the tool known as a distributed processing system and inspired by the biological neurons. These neurons are connected with their weight functions in ANN and approximate any nonlinear system with an accuracy. To use ANN as a controller, the ANN parameters require a tuning by some method. Most popular is back-propagation method based upon gradient descent method [37], [38]. A study for ensuring the stability of the plant around the equilibrium point by using a neural network (NN) for a nonlinear system is discussed in [39]. A linear autoregressive model, which implicitly considers the cyclical behaviour of waves was studied in [40]. By using an autoregressive moving average (ARMA) model wave elevation for a short-term ocean wave forecasting was predicted in [41]. An NN based control is implemented to achieve a setpoint using the plant as nonlinear ARMA (NARMA) model [42]. A demand forecasting and operational planning services in distribution networks with significant distributed energy resources were defined with applications using a nonlinear autoregressive exogenous (NARX) model [43].

\section{B. Motivation and the contribution}

The motivation of writing this paper is to present the performance comparison of the linear (tuned PI) and nonlinear (NARMAX) controller in a nonlinear system, i.e. a WEC in this study. Many papers in the literature have presented a comparative analysis of feed-forward and recurrent type of neural network and a comparative analysis is merely presented with a tuned PI controller in a wave energy harvesting application. Aiming to track a reference value and minimizing the steady-state error a PI control is much suitable. Whereas a PD control, will allow the tuning the transient response but would end up with some steady-state error.

This study presents the response of the WEC as a plant under high uncertainties. The regulation of the stator currents is achieved under both the controllers and an accuracy analysis is presented for tuned PI and NARMAX control.

We apply the idea of using input-output parametric NARMAX model by a neural network (NN) for a nonlinear system identification [44], [45]. The model of the nonlinear process and training method is considered. A nonlinear identification using an NN structure with back-propagation method is used. The weights of the network are updated by the back-propagation method to reduce the difference between the reference model output and the plant output. The objective of the study is to regulate the stator currents at different positions of the translator and investigate the dynamics of both the controllers relative to the oceanic waves, varying with wave amplitude and frequencies. The controllers are validated for the varying position and the speed of the translator as inputs to the model. The controllers provide a correction in the force by regulating the generator stator currents. By keeping the $d$ (direct) axis currents to zero, the reactive power from the generator is controlled. The algorithm of the controls is designed by measuring $d q$ (direct-quadrature) axes currents of the generator and providing a reference $q$-axis current to the controller. The NARMAX controller performs fairly efficiently compared to tuned PI controller in the varying ocean states and maintains the system stable with an enhanced accuracy

In this paper, the PTO with all-electric conversion using a linear generator (LG) is considered[46]-[49]. This paper presents the control of a permanent magnet linear generator (PMLG) by regulating the stator currents and provides a force optimization through an active control. The electrical model of the PMLG is obtained from the equations for a PMSM [50], [51].The stator currents are the controlled variables which are under investigation and related to the force of the translator in this study. The experimental data based verification is from the generator, namely L9[18], based WEC's output installed at Lysekil research site on the west coast of Sweden shown in Fig. 1. 


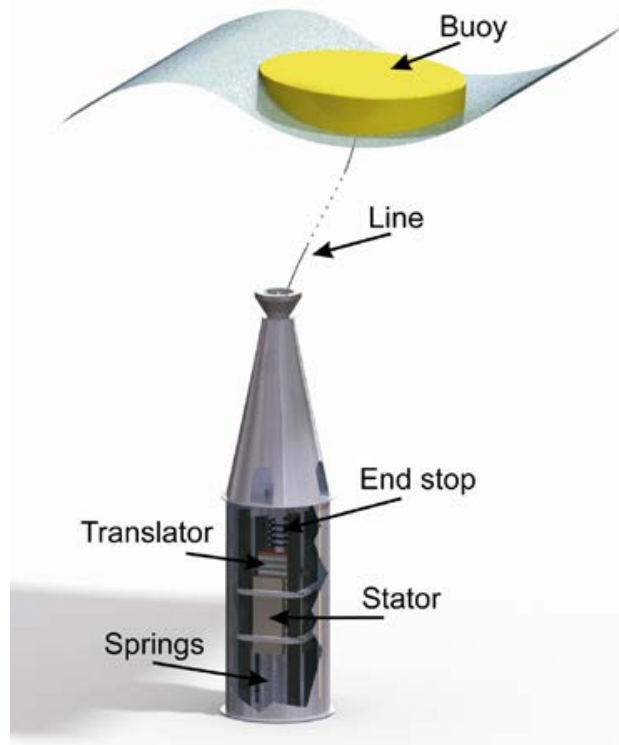

Fig. 1. Description of the WEC developed at Uppsala University [18].

To obtain the desired force, the measured $d q$ currents are regulated by the control. The referenced $d q$ currents are calculated at minimum stator current in the reference controller in a MATLAB/Simulink model. The controllers regulate the $q$-axis stator current since the $q$-axis current is related to the force. Hence a referenced force is predicted with a good accuracy by the NARMAX control. Moreover, both the controllers are utilizing the translator speed from the experimental results as the input obtained in the previous studies [52], [53].

\section{MATHEMATICAL MODELLING OF THE WEC}

\section{A. The model of grid connected WEC}

A WEC consists of a buoy and a PTO mechanism[5455]. The PTO is a combination of a PMLG and a power converter in a back-to-back topology shown in Fig. 2. The generator side control regulates the stator currents at different positions of the translator. A grid side converter, voltage source inverter (VSI), regulates the DC-link and conditions the power before feeding it into the grid.

In Fig. 2, the three-phase voltages, $v_{s, a, b, c}$, are interfaced with a voltage rectifier, VSC, and the rectified directcurrent (DC)-power is transferred to the capacitor, $C$, the DC-link. The DC-link serves as a short-term buffer to smoothen the WEC power. An inverter, VSI, is connected to the DC-link to convert and transfer the power to the alternating-current (AC)-grid/load. The VSC and VSI are controlled by the pulse width modulation (PWM) scheme. At the VSC the stator currents, $i_{s, a, b, c}$, are measured and transformed into $d q$-axis currents, $i_{d, q}$. The measured $q$-axis current estimates the measured force in

$$
\omega_{e}(t)=v_{t}(t) \frac{2 \pi}{\tau}
$$

the Force-measured block. The referenced current, $i_{q, r e f}$ is estimated from the Referenced-Current-Command block

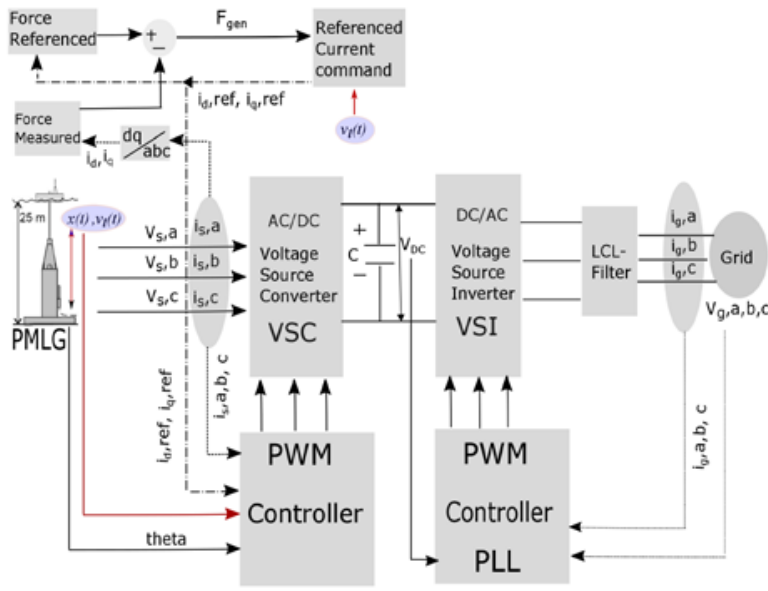

Fig. 2. Block diagram of the system with a heaving WEC.

which depends on the updated value of $F_{g e n} . F_{g e n}$ is the difference of referenced force and the measured force. The referenced force is estimated by the current $i_{q, r e f}$ in a loop to regulate the parameters. The position, $x(t)$ and speed, $v(t)$ of the translator are measured and used to realize the generator's equations to control the switches of the VSC. The VSI is connected to the grid through a harmonic $(L C L)$ filter to reduce the switching ripples of the VSI currents and feeds the grid currents, $i_{g, a, b, c}$, in to the grid. The VSI is controlled through a PWM scheme and a Phase-locked-loop is used to synchronize the VSI to the grid voltages, $V_{g, a, b, c}$.

\section{B. Linear generator modelling}

The three-phase stator in a PMSM can be realized using an equivalent two-phase machine with the phases orthogonal to each other. The $d$ and $q$-axis windings are decoupled magnetically since the flux linkage of two orthogonal windings are zero. Also, since inductance is proportional to the number of turns squared, the magnetizing inductance is the same as the three-phase equivalent. Since the magnetizing inductance and self-

$$
\left.\begin{array}{c}
v_{s d}(t)=R_{s} i_{s d}(t)+\frac{d}{d t} \lambda_{s d}(t)-\omega_{e} \lambda_{s q}(t) \\
v_{s q}(t)=R_{s} i_{s q}(t)+\frac{d}{d t} \lambda_{s q}(t)+\omega_{e} \lambda_{s d}(t) \\
\lambda_{s d}(t)=L_{s} i_{s d}(t)+\lambda_{f d} \\
\lambda_{s q}(t)=L_{s} i_{s q}(t)
\end{array}\right\}
$$

inductance are same, therefore, each $d q$ winding has the same inductance as each phase of a three-phase machine.

The $d$-axis and $q$-axis equations for a linear generator are expressed as in (1) - (3).

where $v_{s d}(t)$ is the $d$-axis voltage and $v_{s q}(t)$ is the $q$-axis voltage, $R_{s}$ is the stator resistance, $i_{s q}(t)$ is the $q$-axis current, $i_{s d}(t)$ is the $d$-axis current, $\lambda_{f d}$ is the excitation linkage flux of the stator due to flux produced by the magnets, $L_{s}$ is the stator inductance and $\omega_{e}(t)$ is the electrical angular frequency is given as in (4). 
where $v_{t}$ is the speed of the translator, $\tau$ is the pole pitch of the PMLG. The force in (5) is the thrust force of the generator, which reacts on the input force in effect of electric conversion [56], [57].

$$
f_{p t o}(t)=\frac{3 \pi}{2 \tau}\left(\lambda_{f d}\right) i_{s q}(t)
$$

The captured mechanical power $\left(P_{p t o}\right)$, when PTO force and the speedare in phase, is obtained in (6)

$$
P_{p t o}(t)=f_{p t o}(t) v_{t}(t)
$$

Total flux in the PMLG is obtained from the following expression in (7) from the conventional source of generator designing[58].

$$
\lambda_{f d}=\frac{\sqrt{6}}{\pi} K_{w} N \tau l_{A}\left(\left(B \lambda_{f d}\right)_{a v}\right)
$$

The converted electrical power can be obtained as

$$
P_{e l}(t)=\frac{3}{2} p\left(\lambda_{f d}\right) \omega_{e}(t) i_{s q}(t)
$$

where $p$ is the number of pole pairs. The parameters appearing in above formulae solely depend on the generator design and summarized in Table I and II with their specific values. Hence, the PTO force can be directly controlled by $i_{s q}^{\text {ref }}$ as in (9) from the referenced current command block in Fig. 1.

$$
i_{s q}^{r e f}=\frac{2 \tau}{3 \pi} \frac{f_{p t o}}{\lambda_{f d}}
$$

To test the different strategies in regular and irregular translator motion, a time-domain simulation model has been implemented in MATLAB/Simulink. In Table II, the

TABLE I

PARAMETERS OF PMLG

\begin{tabular}{lll}
\hline Symbol & Quantity & Unit \\
\hline$K_{w}$ & Winding factor & 0.93 \\
$N$ & No. of turns & 1600 (approx.) \\
$\tau$ & Pole pitch & $45.8 \mathrm{~cm}$ \\
$l_{A}$ & Primary stackwidth & $45 \mathrm{~cm}$ \\
$\left(B \lambda_{f d}\right)_{a v}$ & pm normal airgap (flux average- & $0.7 \mathrm{~T}$ \\
& density over the primary slot) & \\
\hline
\end{tabular}

main electrical and mechanical parameters of the linear generator model are given corresponding to the Lysekil research project conducted by Uppsala University, Sweden.

\section{CONTROL SCHEME}

TABLE II

MAIN PARAMETERS OF THE GENERATOR

\begin{tabular}{llll}
\hline $\begin{array}{l}\text { Electrical } \\
\text { characteristics }\end{array}$ & Unit & $\begin{array}{l}\text { Mechanical } \\
\text { characteristics }\end{array}$ & Unit \\
\hline $\begin{array}{l}\text { Synchronous } \\
\text { inductance }\end{array}$ & $21.2 \mathrm{mH}$ & Nominal speed & $0.7 \mathrm{~m} / \mathrm{s}$ \\
Winding resistance & $0.36 \Omega$ & Stator length & $1.96 \mathrm{~m}$ \\
Rated armature & $40 \mathrm{~A}$ & Stator width & $0.4 \mathrm{~m}$ \\
current & & Translator length & $2.0 \mathrm{~m}$ \\
Rated power & $20 \mathrm{~kW}$ & Translator weight & $2700 \mathrm{~kg}$ \\
Rated voltage & $450 \mathrm{~V}$ & & \\
\hline
\end{tabular}

\section{A. NARMAX Controller model for online parameter tuning}

The literature studies result in approximation and realization theory provides a nonlinear differential model that is suitable for modelling and control the nonlinear systems. Any discrete-time nonlinear system can be represented by the NARMAX model in (10)

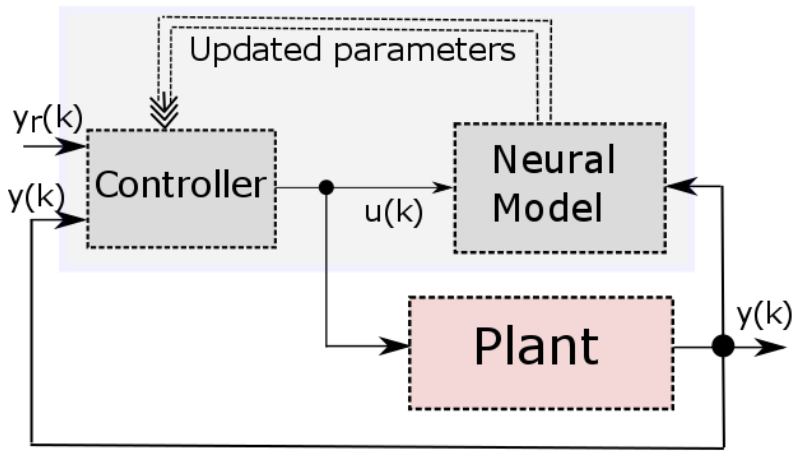

Fig. 3. The control scheme for the estimation of the weights using an NN.

$$
\begin{gathered}
\boldsymbol{y}(\boldsymbol{k})=\boldsymbol{F}[\boldsymbol{y}(\boldsymbol{k}-\mathbf{1}), \ldots ., \boldsymbol{y}(\boldsymbol{k}-\boldsymbol{p}), \\
u(k-1), \ldots u(k-q)]
\end{gathered}
$$

where $F[$.$] is a nonlinear polynomial function, y(k)$ is the output of the model, and $u(k)$ is input to the model.The control scheme using the neural NARMAX model for estimation of parameters is applied to the online tuning of the weighted parameters shown in Fig. 3.

In this paper, the concept of using the input-output parametric nonlinear model in nonlinear system identification by $\mathrm{NN}$ is used [44], [59]. We consider a single hidden layer NN architecture in Fig. 4. The NN is composed of 6 neurons in the input layer, 8 neurons in the hidden layer and one neuron in the output layer. The NARMAX model represents a generic NN with its one step ahead output value $y(k+1)$, depends upon its present input and the past input values (exogenous values). The input values to the $\mathrm{NN}$ are defined $u(k), u(k-1), \ldots . u(k-q+1)$. The input neurons excite the input signal to the hidden layer with proportional weighted parameters, $w_{j i}^{I}(k)$, for each input connecting to the hidden layer. The weighted parameter 
represents the individual weight assigned to the connected $i$ th input neuron to the $j$ th hidden neuron at instant $k$. Each hidden neuron is modeled as nonlinear activation function $\varphi^{j}(\cdot)=\tanh (\cdot)$ at each input. The outputs of the hidden neurons are assigned an individual weight by $w_{j}^{H}(k)$, and processed to the output layer to yield the output of the controller $u(k)$. The $w_{j i}^{I}(k)$ and $w_{j}^{H}(k)$, are the weights for input and hidden layer neurons, where subscript $I, H$ defines the input and hidden layer, $i, j$ defines the number of the input and hidden layer neurons. The aim of the controller is to track and follow the referenced signal by reducing the error between the referenced signal and the plant output, and to do so the weights for each connection in the network are trained and updated in MATLAB using the Levenberg-Marquardt back-propagation algorithm. The output of the network is given in (11).

$$
y(k)=\sum_{j=1}^{q} w_{j}^{H}(k) H_{j}(k)
$$

where $H_{j}(k)$ is the output of the $j$ th hidden neuron and expressed in (12).

$$
\begin{array}{cc} 
& H_{j}(k) \\
& =\varphi^{j}\left(\sum_{i=1}^{q} w_{j i}^{I}(k) u(k-q+1)\right. \\
+ & \left.\sum_{i=1}^{p} w_{j i}^{I}(k) y(k-p+1)\right)
\end{array}
$$

Vector output of the hidden layers denoted as $H_{j}(k)=$ $\left\{H_{1}(k), H_{2}(k) \ldots H_{q}(k)\right\}$ and output weight vector $W_{j}^{H}(k)=$ $\left\{w_{1}^{H}(k), w_{2}^{H}(k) \ldots w_{q}^{H}(k)\right\}$. The output of the neural NARMAX is defined in (13).

$$
y(k)=\sum_{j=1}^{q} w_{j}^{H}(k) H_{j}(k)
$$

We considered the concept of using a feed-forward NARMAX model consists an input layer with 6 neurons, ( $p=q=2$ ) one for each input variable, and 8 neurons in single-hidden layer and an output layer with one neuron. The updated weights are presented in the Appendix.

Representing the NARMAX model from (10) with the regression-equation in (14), where $L$ is the number of unknown parameters, $\varphi_{i}(k)$ is the term in the NARMAX model, $w_{j}(k)$ updated parameters, and $e(k)$ is the estimated error. The mean squared error estimation (MSEE) algorithm is used to minimize the cost-function as in (15) for $N$ data pairs:

$$
y(k)=\sum_{j=1}^{L} \varphi^{j}(k) w_{j}(k)+e(k)
$$

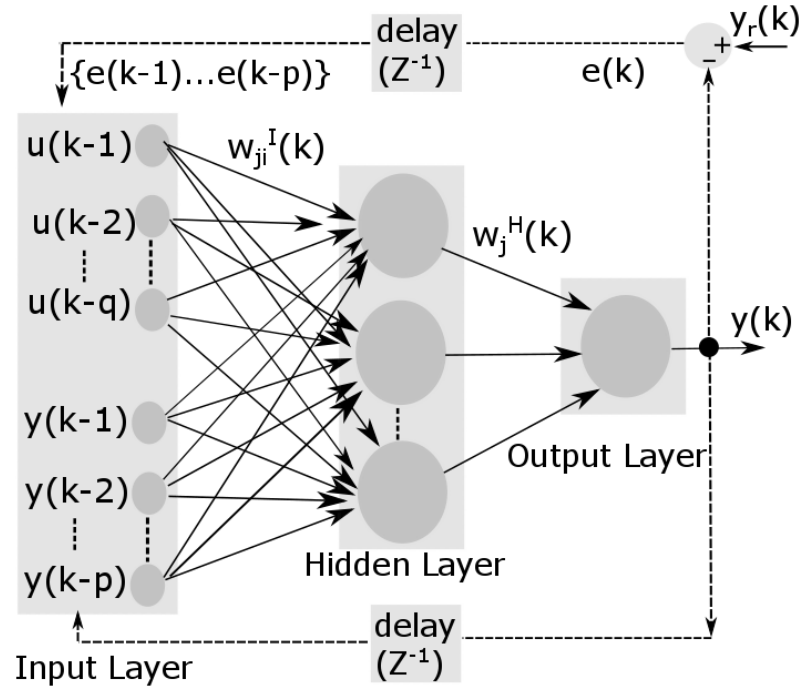

Fig. 4. Structure of the neural NARMAX model.

$$
J(k)=\frac{1}{N} \sum_{i=1}^{N}\left(\left(y_{r}(k)-y(k)\right)^{2}=e^{2}(k)\right.
$$

where $y_{r}(k)$ and $y(k)$ denote desired and actual plant's output, the aim is to reduce the MSEE value so that the output of the plant begins following the desired output.

\section{1) Adjustment of output weight}

The procedure of updating the weights of the output vector is carried out by implementing the following:

$$
\frac{\partial J(k)}{\partial w_{j}^{H}(k)}=\frac{\partial J(k)}{\partial y(k)} \frac{\partial y(k)}{\partial u(k)} \frac{\partial u(k)}{\partial w_{j}^{H}(k)}
$$

where $\frac{\partial J(k)}{\partial w_{j}^{H}(k)}=H_{j}(k), \frac{\partial y(k)}{\partial u(k)}$ is called as Jacobian of the plant and calculated by the mathematical model of the plant. Usually, the model of the plant is unknown and NN-base identifier is used in parallel to the plant to adjust the parameters of the controller[60]. The identification with tuned parameters can approximate the dynamics of the plant/system. Each element in $w_{j}^{H}(k)=$ $\left[w_{1}^{H}(k), w_{2}^{H}(k) \ldots w_{q}^{H}(k)\right] \quad$ is updated as $w_{j}^{H}(k+1)=$ $w_{j}^{H}(k)+\Delta w_{j}^{H}(k)$.

where $\Delta w_{j}^{H}(k)=\eta e(k) \frac{\partial y(k)}{\partial u(k)} H_{j}(k), \eta$ defines the learning rate. The learning rate is chosen by the discrete Lyapunov stability method and can be found in details in [61]. Which satisfies the criteria: $0<\eta \leq$ $\frac{2}{\left[\frac{\partial y(k) \partial u(k)}{\partial u(k) \partial w_{j}^{H}(k)}\right]^{2}}$.

\section{2) Adjustment of input weight}

The input weight vectors are updated as in (17)

$$
\frac{\partial J(k)}{\partial w_{j i}^{I}(k)}=\frac{\partial J(k)}{\partial y(k)} \frac{\partial y(k)}{\partial u(k)} \frac{\partial u(k)}{\partial H_{j}(k)} \frac{\partial H_{j}(k)}{\partial \varphi^{j}(k)} \frac{\partial \varphi^{j}(k)}{\partial w_{j i}^{I}(k)}
$$


where $\frac{\partial u(k)}{\partial H_{j}(k)}=w_{j}^{H}(k)$ since linear activation function of unity gain is used for output layer and $\frac{\partial H_{j}(k)}{\partial \varphi^{j}(k)}$ as a tangent hyperbolic function is used for hidden layer. Each element $\operatorname{in}_{j i}^{I}(k)$ is updated in a similar way as in previous sub-section by updating $\Delta w_{j i}^{I}(k)$.

where $\quad \Delta w_{j i}^{I}(k)=\eta e(k) \frac{\partial y(k)}{\partial u(k)} H_{j}(k) \frac{\partial \varphi^{j}(k)}{\partial w_{j i}^{I}(k)^{\prime}}$ the updated parameters are presented as a function of estimated gain $k_{g}=\left[K_{1} K_{2} K_{3} \ldots\right]$. The estimated gains are presented in the Appendix B.

\section{B. PI-Controller model for tuning the parameters}

The controller design is based on a Single-Input-SingleOutput (SISO) control topology. The controller, $C(s)$, is connected with the plant, $G(s)$, as shown in Fig. 3. $u(k)$ is the controller output and defined as $U(s)$ in s-domain. The mathematical relation of the controller and plant are presented in (18). $E(s)$ is the error between the referenced $Y_{r}(s)$ and the measured signal $Y(s)$.

$$
\left.\begin{array}{c}
Y(s)=G(s) U(s) \\
U(S)=C(s) E(s) \\
E(s)=Y_{r}(s)-Y(s)
\end{array}\right\}
$$

Solving for $Y(s) / Y_{r}(s)$, where $Y(s)$ is the output and $Y_{r}(s)$ is the referenced input in the s-domain, yields (19).

$$
\frac{Y(s)}{Y_{r}(s)}=\frac{G(s) C(s)}{1+G(s) C(s)}=\frac{H(s)}{1+H(s)}
$$

Equation(1) and (2) can be presented in the Laplace domain:

$$
\begin{gathered}
v_{s d}=i_{s d}\left(R_{s}+s L_{s}\right)+s\left(\lambda_{f d}\right)-\omega_{e} L_{s} i_{s q} \\
v_{s q}=i_{s q}\left(R_{s}+s L_{s}\right)+\omega_{e}\left(L_{s} i_{s d}+\lambda_{f d}\right)
\end{gathered}
$$

Representation for the $d$-axis current,

$$
i_{s d}=\frac{1}{\left(R_{s}+s L_{s}\right)}\left(v_{s d}+\omega_{e}\left(L_{s} i_{s q}\right)\right)
$$

Representation for the $q$-axis current,

$$
i_{s q}=\frac{1}{\left(R_{s}+s L_{s}\right)}\left(v_{s q}-\omega_{e}\left(L_{s} i_{s d}+\lambda_{f d}\right)\right)
$$

The stator/plant transfer function is obtained from (22) and (23). Since both the stator resistance and inductance are equivalent in the $d q$ reference frame, therefore the same plant can be used for the controller transfer function as in (34).As a common practice to decouple the respective control loops, substitute control variables are obtained in (25)-(26).These variables are the outputs of the controller as functions of compensation parameters $c_{p, d}(s)$ and $c_{p, q}(s)$ and the errors in the current as inputs to the controller.

$$
\begin{gathered}
G(s)=\frac{i_{s d}(s)}{\left(v_{s d}+\omega_{e}\left(L_{s} i_{s q}\right)\right)} \\
=\frac{i_{s q}(s)}{\left(v_{s q}-\omega_{e}\left(L_{s} i_{s d}+\lambda_{f d}\right)\right)} \\
=\frac{1}{\left(R_{s}+s L_{s}\right)} \\
u_{d}(s)=\left(v_{s d}+\omega_{e}\left(L_{s} i_{s q}\right)\right) \\
u_{q}(s)=\left(v_{s q}-\omega_{e}\left(L_{s} i_{s d}+\lambda_{f d}\right)\right) \\
u_{d}(s)=c_{p, d}(s)\left(i_{r e f}^{s d}-i_{s d}\right) \\
u_{q}(s)=c_{p, q}(s)\left(i_{r e f}^{s q}-i_{s q}\right)
\end{gathered}
$$

Inserting (25) into (22) and replacing $u_{d}(s)$ by (27) yields a first-order closed loop transfer function for the $d$ axis in (29). The PI compensator $c_{p}(s)$ is defined in (34) for $d$-axis compensation.

$$
\begin{gathered}
\frac{i_{s, d}(s)}{i_{s, d}^{r e f}(s)}=\frac{c_{p, d}(s)}{\left(R_{s}+s L_{s}+c_{p, d}(s)\right)} \\
\mathrm{c}_{p, d}(s)=\frac{K_{i, d}}{s}+K_{p, d}
\end{gathered}
$$

The closed-loop transfer function yields in (31)

$$
\begin{aligned}
& \frac{i_{s, d}(s)}{i_{s, d}^{r e f}(s)}=\frac{\frac{K_{p, d}}{L_{s}}\left[\frac{K_{i, d}}{K_{p, d}}+s\right]}{s^{2}+\left(\frac{R_{s}+K_{p, d}}{L_{s}}\right) s+\frac{K_{i, d}}{L_{s}}} \\
& \frac{i_{s, d}(s)}{i_{\text {ref }}^{s, d}(s)}=\frac{1}{1+s\left(\frac{L_{S}}{K_{p, d}}\right)}
\end{aligned}
$$

To achieve a transient behaviour of a first-order system, it is common practice to cancel out the pole of the stator transfer function in (22) with the zero of the PIcompensator (30) results in the condition: $\frac{K_{i, d}}{K_{p, d}}=\frac{R_{s}}{L_{s, d}}$.

Similarly, the pole-zero compensation is applied for $q$ axis and yields (33) for $\frac{K_{i, q}}{K_{p, q}}=\frac{R_{s}}{L_{s, q}}$, where $L_{s, d}=L_{s, q}$.

$$
\frac{i_{s, q}(s)}{i_{s, q}^{r e f}(s)}=\frac{1}{1+s\left(\frac{L_{s}}{K_{p, q}}\right)}
$$

The obtained first-order dynamic system of the closed-loop defines the parameters of PI-regulator.

\section{Stability analysis of plant and the controller transfer function of PI-controller}

The total loop gain can be expressed as the multiplication of both the controller and plant transfer functions and yields in (34). 


\section{IV. $\quad$ TEST CASE SPECIFICATIONS AND TIME DOMAIN ANALYSIS}

$$
H(s)=\frac{(s+1)}{s\left(1+s\left(\frac{L_{s}}{R_{s}}\right)\right) R_{s}}
$$

Solving for $R_{s}=0.36 \Omega$ and $L_{s}=21.2 \mathrm{mH}$ in (34) becomes (35).

$$
H(s)=\frac{(s+1)}{s(1+s(0.0589)) 0.36}
$$

A Bode plot is presented for the controller and plant transfer function in Fig. 5. The plant transfer function has a phase margin at $44.4 \mathrm{rad} / \mathrm{sec}$. This system will oscillate towards steady state values without a controller. The stability point is noted at $R_{s} / L_{s}=17.1 \mathrm{rad} / \mathrm{sec}$. By cancelling out the pole of the plant with the zero of the controller, the phase margin will stay at -90 degrees. It can be verified from the pole-zero map in Fig. 6 that a zero is located at $\omega=1 \mathrm{rad} / \mathrm{sec}$ and a pole is located at $\omega=$ $17.1 \mathrm{rad} / \mathrm{sec}$. It can be noted that the poles and zero are on the left side on the pole-zero map which defines a suitable condition for the stability.

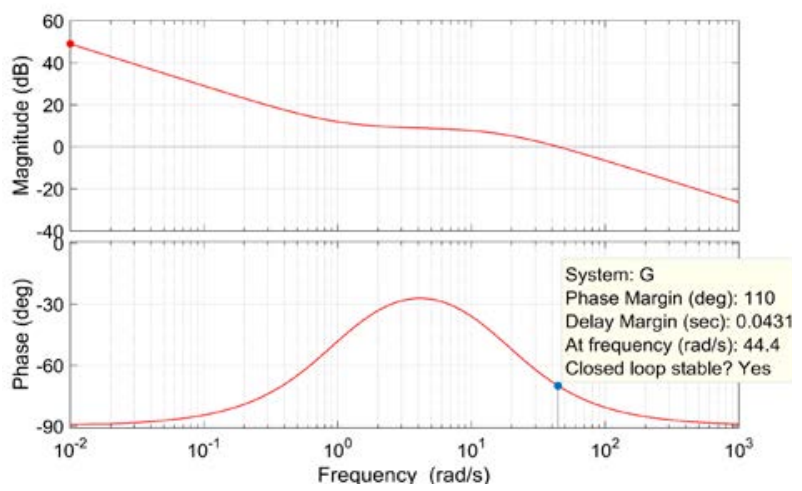

Fig. 5. Bode plot of plant and the controller open loop transfer function.

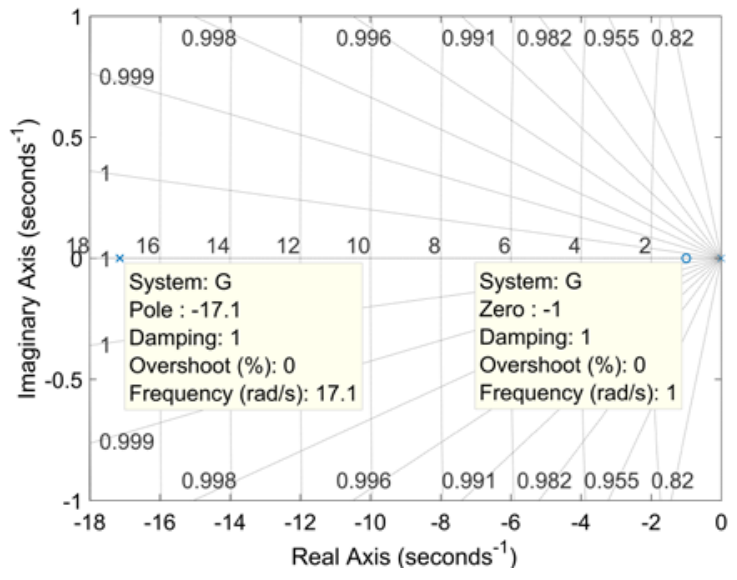

Fig. 6. Pole-Zero map of the plant and controller open loop transfer function.
In order to investigate the behaviour of the controller, different ocean waves of different characteristics have been considered in three cases. To test the control strategy with the heaving WEC in regular and irregular translator motions, a time-domain simulation model has been implemented in MATLAB/SIMULINK. The Simulink results associated with different cases, regular and irregular waves, entails the robustness and redundancy of the controller.

The control method is applied to a regular motion of the translator of an amplitude of $0.5 \mathrm{~m}$ and $\omega=1.047 \mathrm{rad} / \mathrm{s}$ (Case I)for one wave period of $6 \mathrm{~s}$ and two different cases for irregular translator motion of an amplitude $0.625 \mathrm{~m}$ with a frequency of $\omega=1.047 \mathrm{rad} / \mathrm{s}$ (Case II), and the translator's motion of an amplitude of $0.975 \mathrm{~m}$ with the frequency of $\omega=1.1423 \mathrm{rad} / \mathrm{s}$ (Case III), for the lowfrequency and high-frequency spectrum, respectively used as the inputs to the model for the investigation. The translator positions for Cases II and III have been recorded in offshore experiments at Lysekil research site [52], [53].The mechanical motion of the translator is discussed in terms of speed and force, for electrical variables they are referred to by the angle-based values of $\theta$ and $\omega_{e}$. The translator electrical angle, $\theta$, covers an electrical cycle for each time the translator mechanically travels one length of the machine. The voltage developed in the stator windings depends on the rate of change of the flux linkage. Since the PMLG design is symmetric, the variables of the zero sequence are zero. Moreover, the $d$ axis component of the stator current is normally controlled to zero to reduce the power loss in the stator of the PMLG[19]. The energy transferred from the linear generator to the voltage source converter (VSC) in current mode $E_{c}$ can be expressed as a balance between the average energy extracted by the PTO system $E_{p t o}$ and the linear generator copper losses $\left(E_{\text {loss }}\right)$ in (36).

$$
E_{C}=E_{\text {pto }}-E_{\text {loss }}
$$

The PMLG delivers the power to the DC-link through the VSC. The converter is configured for the PMLG in a generator mode. Another side of the DC-link is connected to a voltage source inverter (VSI) followed by a filter and an electric grid. The VSI controls the DC-link and keeps it constant to the desired level.

\section{A. Accuracy of the controller}

The accuracy of the controller is calculated by using the correlation coefficient $(R)$ and a relative square root error $(R R E)$ in (37) and (38). A correlation coefficient is found in the performance of the controller in the low and highfrequency spectrum. It is the ratio between targeted and simulated values to achieve a percentage of variability in terms of accuracy by introducing a coefficient of determination $\left(R^{2}\right)$. Where $x_{i}$ is the reference (target) value, $\bar{x}$ is the mean of the target value, $y_{i}$ is the measured value, $\bar{y}$ is mean of the measured value and $N$ is the 
number of data pairs. The obtained results for the different irregular translator positions are depicted in Table III in Section V.

$$
\begin{gathered}
R=\frac{\sum_{i=1}^{N}\left(x_{i}-\bar{x}\right)\left(y_{i}-\bar{y}\right)}{\sqrt{\sum_{i=1}^{N}\left(x_{i}-\bar{x}\right)^{2} \sum_{i=1}^{N}\left(y_{i}-\bar{y}\right)^{2}}} \\
R R E=\frac{\sqrt{\sum_{i=1}^{N}\left(x_{i}-y_{i}\right)^{2}}}{\sqrt{\sum_{i=1}^{N}\left(y_{i}-\bar{y}\right)^{2}}}
\end{gathered}
$$

\section{RESULTS AND DISCUSSION}

When a nonlinear or an adaptive controller is used, a time domain simulation study is showing how the parameters convergence is usually included when the weights of the parameters reach a stable point asymptotically. In this section, we present the time domain based analysis and results for the three cases (I, II, and III). The proposed control is compared to a tuned PI-controller and the compared results are presented for the force control and the currents regulation. The proportional gain accelerates the error convergence time while the integral gain reduces the rise time and increases the overshoot. Therefore there is a trade-off between these parameters to eliminate the steady-state errors. The selected proportional gain $\left(K_{p}\right)$ is 66.56 and the integral gain $\left(K_{i}\right)$ is 1131 for a stable operation. The comparison is done for Case II and Case III to investigate the control capacity during the varying states. The investigation of Case I is utilizing a sinosoidal wave of one wave period of $6 \mathrm{~s}\left(T_{e}=6 \mathrm{~s}\right)$ and a wave height of $0.5 \mathrm{~m}\left(H_{s}=0.5 \mathrm{~m}\right)$ which dipicts a regular motion of the translator. The experimental data are utilized as inputs for the investigation of Case II and Case III. The data for Case II is considered for first $29 \mathrm{~s}$, starting from zero and sampled for $29 \mathrm{~s}$, while the data utilized in Case III, starts from $30 \mathrm{~s}$ and utilized for the next $30 \mathrm{~s}$, ranging from $30 \mathrm{~s}$ to $60 \mathrm{~s}$, to investigate the performance of the controller. Fig. 7 presents the input waves: used in the study for three different cases (I, II, and III). A standard PC with 3.5 $\mathrm{GHz}$ microprocessor was used for the Case (I, II, and III) investigation. Due to the limitation of the PC microprocessor, the full experimental data are not used. A stable, robust and vigorous behaviour of the controller is expected in each case under the investigation, and Case
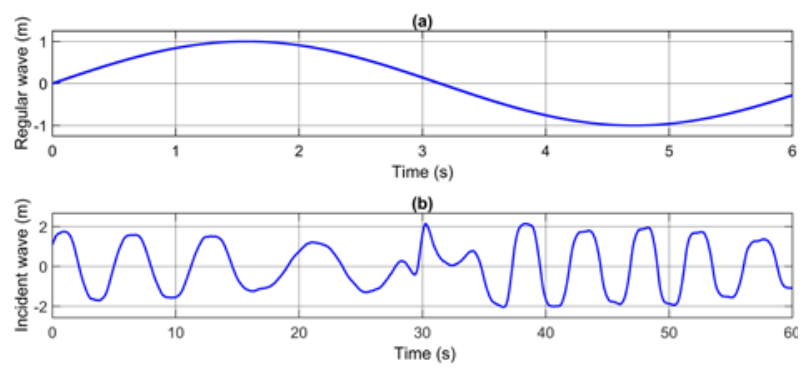

Fig. 7. Input wave data; (a) A regular wave for one wave period of $6 \mathrm{~s}$ in Case I; (b) The irregular waves for, Case II: 0-29 s, and Case III: 30-60 s.

III presents a high varying nature of the waves in terms of the translator speed. Therefore, we present most of the results for Case III to present the effectiveness of the controller in frequently varying states under the subsection B. The results presented in Fig. 11-Fig. 10 are to verify the controller performance in both Case II and Case III.

\section{A. Controller performance for Case I}

The performance of the controller is investigated in Case I for a regular motion. The regular motion is chosen for one wave period of $6 \mathrm{~s}\left(T_{e}=6 \mathrm{~s}\right)$ only. The stator $d q$ axes currents, $i_{s d}$, and $i_{s q}$, from the PMLG,are shown in Fig. $\underline{5}$. The output of the $d q$ transform is normally the DC values of the signal, the variable amplitude nature of the generator results in a sinusoidal reference. In Fig. 8 (a), the fluctuation is very small compared to the reference and hence it is negligible. Almost zero $d$-axis component was found after the de-coupling compensation terms. The error compared to the reference value is negligible. The maximum error of the current value is $0.4 \mathrm{~A}$, which is fairly negligible compared to the $q$-axis component of $26 \mathrm{~A}$, as shown in Fig 8 (b). The controller performance is presented for the currents and the force control for one period of the regular motion, see Fig. 7. The controller continuously tracks the prescribed generator $d$-axis and $q$ axis currents and force with less phase shift or an amplitude shift. Keeping almost zero $d$-axis current, there is no reactive power production from the generator and hence, producing unity power factor. A force controller is designed to estimate the referenced force from the estimated $i_{s q_{-} r e f}$ current and to update a new referenced force used as an input to the force controller block. The actual graphs are overlapping each other as shown in Fig. 8 (c). The force output is based upon the parameters and

(a)
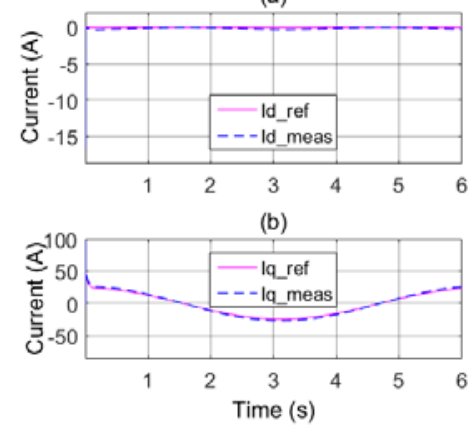

Fig. 8. Controller tracking in Case I. (a) $d$-axis referenced and measured currents; (b) $q$-axis referenced and measured currents; (c) Force- referenced and the forcegenerated in Case I.

utilized in the simulation as an input for a regular motion.

\section{B. Controller performance for Case II and Case III}

In this section, the results based on the experimental data are presented based on the data from the offshore operation for the verification of the control model. The 
control capacity of the proposed controller is compared to a traditional PI-controller and the compared results are presented. The aim of this investigation is to present the control capacity of the controller during the irregular translator motions and to verify the redundancy and robustness of the controller under the high degree of variations similar to a real ocean stochastic wave of varying periods and the variable frequency. It is verified through the experimental data available from the generator, namely, L9. We implemented a force control by regulating the currents of the generator and achieved improved power conversion efficiency (PCE) from the VSC to the DC-bus. Position, speed, and frequency are shown in Fig.9 for Case III. The irregular translator positions for Case II and III are used for the investigation. The maximum speed of the translator is $0.73 \mathrm{~m} / \mathrm{s}$, shown in Fig.9. The force and speed associated with a commonplace for an irregular translator motion with $\omega=1.0471$ and $1.1423 \mathrm{rad} / \mathrm{s}$ are extracted in the time domain in Fig. 10. Fig. 10 (a) presents the control capacity of the PIcontroller for the force control depending on the regulated currents and the proposed control capacity is presented for the force control for both the cases (I and II) under investigation in Fig. 10 (b). In Fig. 10 (a), it can be noted that the PI controller has larger fluctuations, during the investigations, due to the behaviour of proportional and integral gains. The control is able to eliminate the steady-state errors with noticeable overshoots during the transient periods. Therefore, the regulation of the currents is not precisely achieved. The PI-control strategy is not able to bring a resonance condition for the force and the speed hence the power capture ratio could not be guaranteed to maximize. A power capture ratio defines the extraction of the power from the waves to the converter. In Fig. 10 (b), the currents are regulated precisely and controls the force to achieve a resonance with the speed. The force and the speed are in almost resonance condition, the speed is almost in-phase with the force. By this way, the WEC extracts the power from the waves with an improved efficiency. A correlation coefficient for Case II (low-frequency spectrum) and for Case III (high-frequency spectrum) is obtained with $R R E$ and reported in Table III. The three-phase terminal voltages and currents from the generator are shown in Fig.11.

TABLE III

VARIABILITY OF THE CONTROLLERS.

\begin{tabular}{llcccl}
\hline \hline Control & $\begin{array}{l}\omega \\
(\mathrm{rad} / \mathrm{s})\end{array}$ & $R$ & $R^{2}$ & Accuracy & $R R E$ \\
\hline Case II & & & & & \\
$\mathrm{NN}$ & 1.0471 & 0.9763 & 0.9561 & $95.61 \%$ & 0.03735 \\
$\mathrm{PI}$ & 1.0471 & 0.7352 & 0.5405 & $54.05 \%$ & 0.4595 \\
\hline Case III & & & & & \\
NN & 1.1423 & 0.9227 & 0.8565 & $85.65 \%$ & 0.0769 \\
PI & 1.1423 & 0.6958 & 0.4842 & $48.42 \%$ & 0.5158 \\
\hline \hline
\end{tabular}

The stable behaviour of the proposed controller can be appreciated in high-frequencyspectrum regions with a

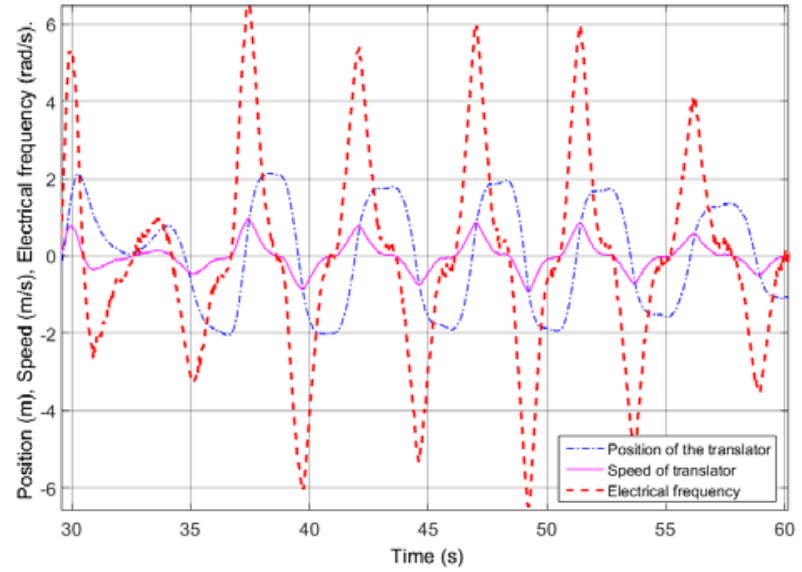

Fig 9. Position, speed, and electrical frequency of the translator in Case III.
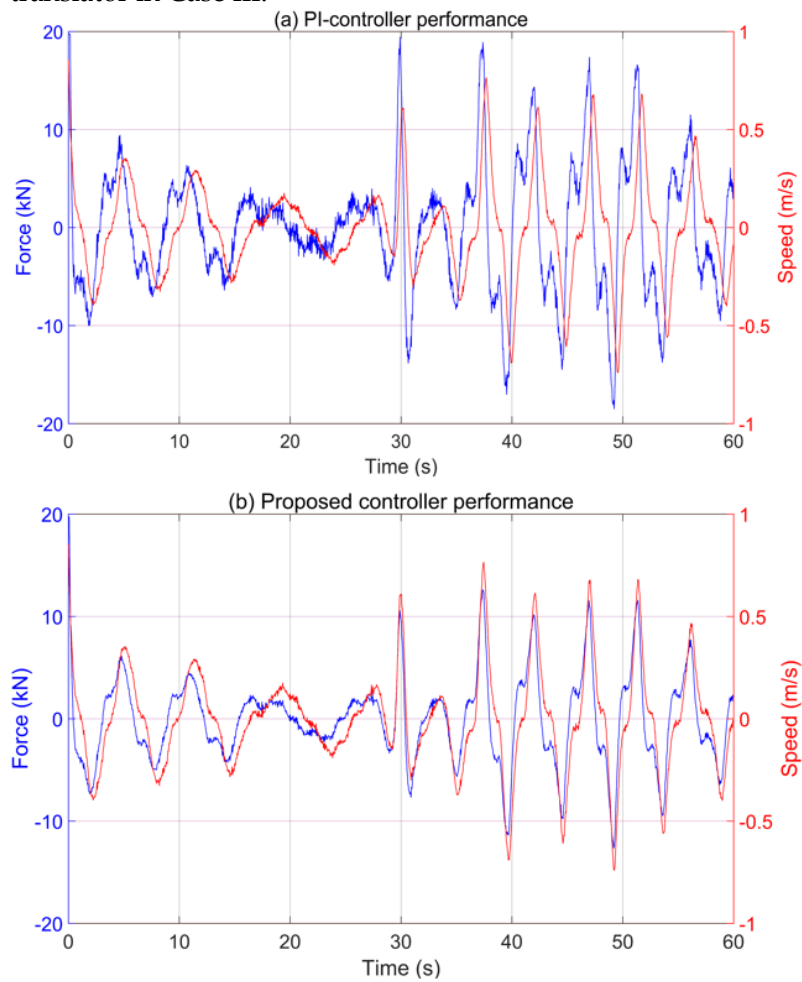

Fig. 10. The acting force and speed in Case II and Case III of the irregular translator motions. (a) PI-controller performance; (b) Proposed control performance.

less margin of errors due to the online tuning of the weights which provides a precise control under the higher nonlinear variations. The controller performs equally vigorous and timid during the performance in varying ocean conditions.

Since Case III has a higher fluctuating and nonlinear behaviour, therefore most of the results are discussed to present the performance of the controller in a higher nonlinear variation. The regulation of the stator currents is presented with a comparison to a PI-controller for Case II and Case III to verify the robustness of the proposed controller for the investigated cases as shown in Fig. 12 and Fig. 13. The behaviour of the PI-controller for the $d q$ currents regulation is shown in Figure 12.

The results in Fig. 12 (a), clearly depicts that the measured $d$-axis current has larger fluctuations which 
leads to a reactive power generation and higher losses from the generator. In Case II, the control capacity of the controller was noted up-to $54.05 \%$. On the other hand, the control capacity is reduced to $48.42 \%$ in Case III. This condition occurs due to the fluctuating nature of the PI-

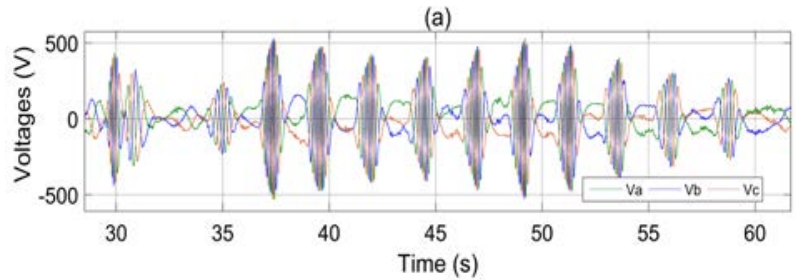

(b)

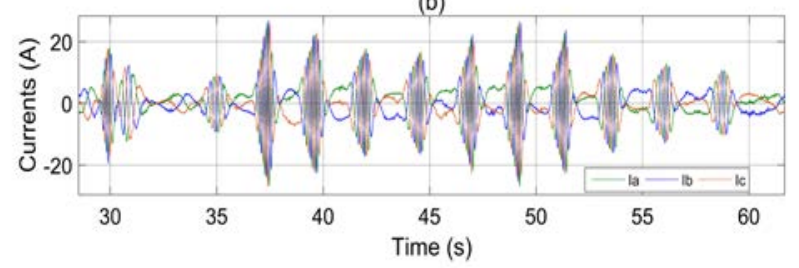

Fig. 11. PMLG output in Case III. (a) Phase voltages, (b) Controlled line-currents.

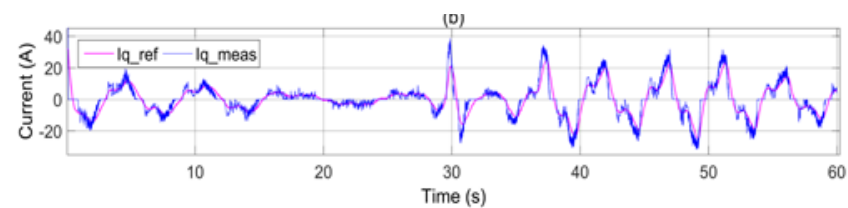

Fig. 12. The performance of PI-controller for Case II, 0-29 s, and Case III, 30-60s. (a) d-axis referenced and measured currents; (b) qaxis referenced and measured currents.
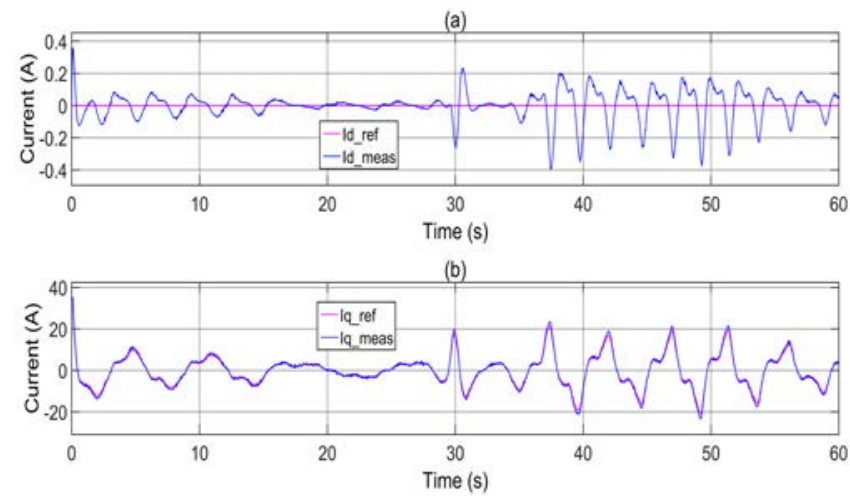

Fig. 13. Performance of the proposed controller for Case II, 0-29 $\mathrm{s}$, and Case III, 30-60s. (a) $d$-axis referenced and measured currents; (b) $q$-axis referenced and measured currents.

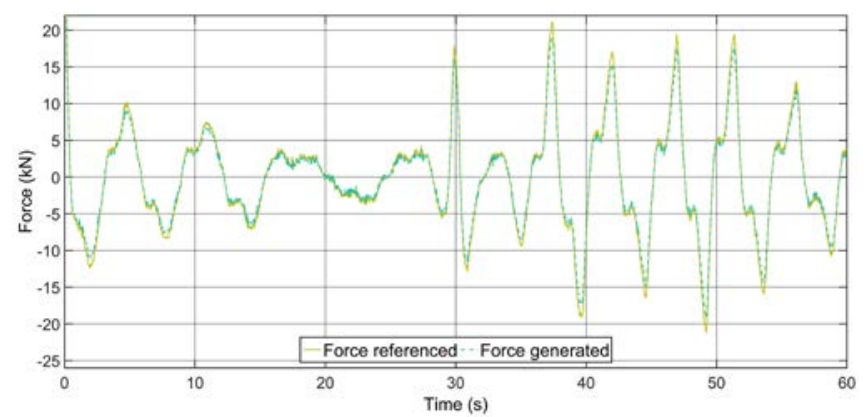

Fig. 14. Referenced and generated force for Case II, 0-29 s, and Case III, 30-60 s in the proposed control.

-controller during the transient states and which leads to a larger phase-shift between the force and the speed. The traditional PI-control is not fully able to regulate the currents in the frequent nonlinear states. Therefore, the measured $d$-axis current becomes larger and increases the losses and the reactive power of the PMLG.

The proposed control scheme adequately improved the control capacity of the controller and regulated the currents, precisely. This promising control of the generator currents provides an optimal force control by the proposed control scheme as presented in Fig.10 (b) and Fig. 13. The $d q$-axis currents are precisely controlled with a noticeable amount of accuracy. The losses and the errors are reduced up-to a great extent. By regulating the $q$-axis current the referenced force is predicted and tracked precisely with a slight error deviation as shown in Fig. 14. The total power extracted, the power delivered to the converter and the power at the DC-bus are shown in Fig. 15 for Case III of irregular translator motion. In Fig. 15, the mean mechanical power available is $9.2 \mathrm{~kW}$ and the delivered active electrical power to the DC-bus is $7.38 \mathrm{~kW}$. This presents the power conversion efficiency (PCE), i.e. $80.21 \%$, for Case III of the irregular translator motion of a frequency, $\omega=1.1423 \mathrm{rad} / \mathrm{s}$. The power losses are due to the resistive losses in the generator, sea cables and losses at the converter. The results presented in Fig. 10-Fig. 15, present the robust control capacity of the proposed controller during the irregular variations of the translator.

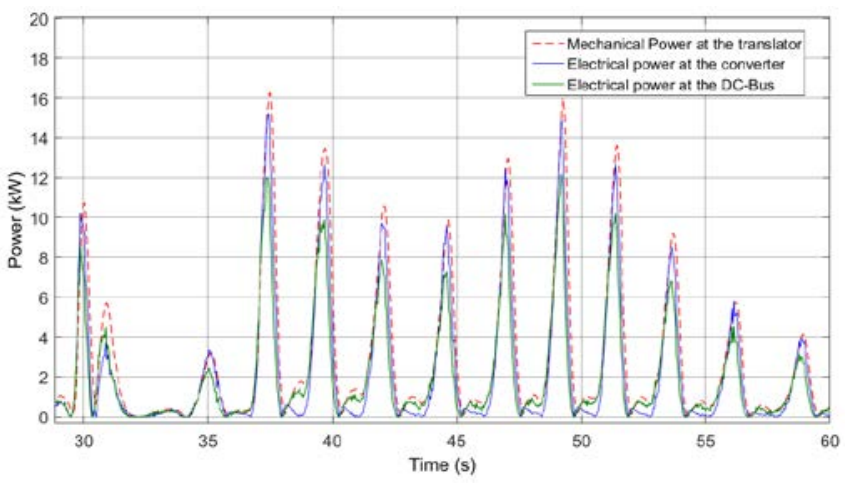

Fig. 15. Power captured from the PTO and delivered DC-bus power in Case III.

\section{CONCLUSION}

In this paper, a verification of the nonlinear control for controlling the force of the generator by regulating the stator currents of the generator is presented. Moreover, data from the offshore operation is utilized as inputs to verify the control and tracking of the generator currents in two cases of irregular translator motion. The accuracy of the controller with a nonlinear plant has been analyzed, compared to a tuned PI-controller, and verified through the detailed simulation. The transfer function of the PI controller and the plant is derived and the stability of the control with the plant is studied and results presented in the Bode plot and the pole-zero map. The $d q$ axes currents are regulated, precisely and the $d q$-axes referenced currents are tracked with the minimum errors. A correction in the force is predicted to the force controller and the force required by the PMLG is 
regulated by regulating the $q$-axis current. It can be noted that the WEC operating under NARMAX control, when the translator motion is not regular, has reduced the generator losses by regulating the minimal stator currents with an improved accuracy. The proposed controller produces small ripples in the measured $d$-axis current in comparison to the measured $d$-axis current by a PIcontroller. The ripples are negligible in comparison to the regulated $q$-axis current and an improved and prominent active power generation from the generator is achieved.

A grid-connected system brings a more smoothen way to handle the DC-bus. It is controlled and maintained steady by the inverter through a grid side control. It reduces the power fluctuations into the system and the power quality could be enhanced. A separate study will be investigated with an experimental verification of the controller in near future.

\section{APPENDIX}

The updated parameters during the process are shown below. The total number of the parameter can be estimated as $N_{w}=(I+1) H+(H+1) O=65$, where $I, H$, and $O$ are the number of neurons in the input, hidden and the output layers. In this study, we used $I=6, H=8$, and $O=1$. The green curve shown in Appendix A is one of the parameters out of 65 . The updated gains are shown in Appendix.

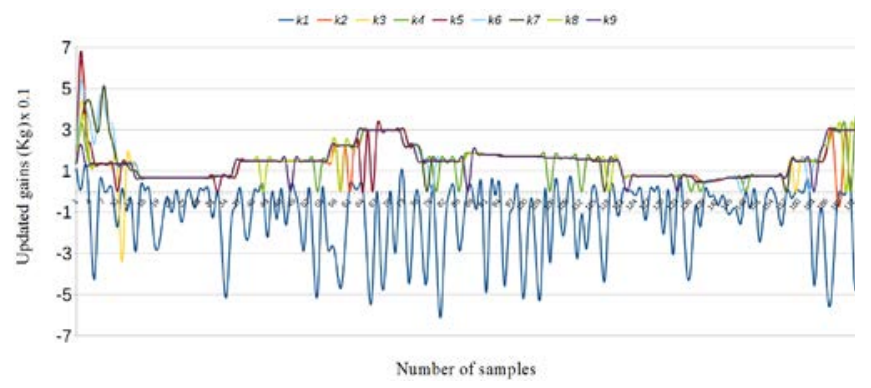

Appendix. The updated gain parameters.

\section{REFERENCES}

[1] E. Callaway, "Energy: To catch a wave," Nature, vol. 450, no. 7167. pp. 156-159, 2007.

[2] Ocean Energy Systems, “Annual Report Ocean Energy System 2015," 2015.

[3] R. Pascal, A. Combourieu, S. Nauwelaerts, and A. Foschini, "Experimental assessment of an innovative management system for mooring loads," in Proceedings of the Twelfth European Wave and Tidal Energy Conference, 2017, pp. 645-50.

[4] S. J. Beatty et al., "Experimental and numerical simulations of moored self-reacting point absorber wave energy converters," Proc. Int. Offshore Polar Eng. Conf., vol. 2015-Janua, pp. 924935, 2015.

[5] D. Vicinanza, P. Contestabile, and E. Di Lauro, “Overtopping breakwater for wave energy conversion: status and perspectives," in Proceedings of the Twelfth European Wave and Tidal Energy Conference, 2017, pp. 1194-1199.

[6] G. Colicchio, I. Santic, M. Peviani, A. Danelli, and A. Colucci, "Numerical and experimental analysis of the efficiency of an
Oscillating Water Column," in Proceedings of the Twelfth European Wave and Tidal Energy Conference, 2017, pp. 1170-78.

[7] M. C. Sousounis, L. K. Gan, A. E. Kiprakis, and J. K. H. Shek, "Direct drive wave energy array with offshore energy storage supplying off-grid residential load," IET Renew. Power Gener., vol. 11, no. 9, pp. 1081-1088, 2017. DOI: 10.1049/ietrpg.2016.0032, [2017].

[8] A. Bahaj, "Generating Electricity from the Oceans," Renew. and Sust. Energy Reviews, vol. 15, no. 7, pp. 3399-3416. DOI:10.1016/j.rser.2011.04.032, [2011].

[9] F. Gardner, "Power-take-off system with spring characteristics for resonating, heaving wave energy converters," in Proceedings of the Twelfth European Wave and Tidal Energy Conference, 2017, pp. 1163-1167.

[10] A. M. Viselli, A. J. Goupee, and H. J. Dagher, "Model Test of a 1:8-Scale Floating Wind Turbine Offshore in the Gulf of Maine 1," J. Offshore Mech. Arct. Eng., vol. 137, no. 4, p. 041901, 2015.

[11] X. Peng and J. Wild, "Innovative Microgrid Solution for Renewable Energy Integration within the REIDS Initiative," in Energy Procedia, 2017, vol. 143, pp. 599-604. DOI: 10.1016/j.egypro.2017.12.733

[12] A. Iturrioz et al., "Metocean characterization of BiMEP for WEC design," in Proceedings of the Twelfth European Wave and Tidal Energy Conference, 2017, pp. 754-759.

[13] M. Leijon et al., "Wave energy from the north sea: Experiences from the Lysekil research site," Surv. Geophys., vol. 29, no. 3, pp. 221-240, 2008. DOI: 10.1007/s10712-008-9047-x, [2008].

[14] P. Cross et al., "U.S. Navy Wave Energy Test Site - Early Findings," in Proceedings of the Twelfth European Wave and Tidal Energy Conference, 2017, pp. 729-739.

[15] A. Mendonça et al., "An integrated tool for modelling oscillating water column (OWC) wave energy converters (WEC) in vertical breakwaters," J. Hydro-Environment Res., vol. 19, pp. 198-213, 2018. DOI: 10.1016/j.jher.2017.10.007, [2018].

[16] S. Armstrong, E. Cotilla-Sanchez, and T. Kovaltchouk, "Assessing the Impact of the Grid Connected Pacific Marine Energy Centre Wave Energy Farm," IEEE J. Emerg. Sel. Top. Power Electron., vol. 3, no. 4, pp. 1-1, 2015. DOI: 10.1109/JESTPE.2015.2429577, [2015].

[17] A. Parwal et al., "Wave Energy Research at Uppsala University and The Lysekil Research Site, Sweden: A Status Update," in Proceedings of the 11th European Wave and Tidal Energy Conference, 2015.

[18] E. Lejerskog, C. Boström, L. Hai, R. Waters, and M. Leijon, "Experimental results on power absorption from a wave energy converter at the Lysekil wave energy research site," Renew. Energy, vol. 77, pp. 9-14, 2015. DOI: 10.1016/j.renene.2014.11.050, [2015].

[19] A. F. de O. Falcão, "Wave energy utilization: A review of the technologies," Renew. Sustain. Energy Rev., vol. 14, no. 3, pp. 899-918, 2010. DOI: 10.1016/j.rser.2009.11.003, [2009].

[20] J. C. C. Henriques, W. Sheng, A. F. O. Falcão, and L. M. C. Gato, "A comparison of biradial and wells air turbines on the Mutriku breakwater OWC wave power plant," in Proceedings of the International Conference on Offshore Mechanics and Arctic Engineering - OMAE, 2017, vol. 10.

[21] S. Peretta, P. Ruol, L. Martinelli, A. Tetu, and J. P. Kofoed, "Effect of a negative stiffness mechanism on the performance of the WEPTOS rotors," 6th Int. Conf. Comput. Methods Mar. Eng., 2015.

[22] O. Gaidai, C. Ji, C. Kalogeri, and J. Gao, "SEM-REV energy site extreme wave prediction," Renew. Energy, vol. 101, pp. 894-899, 2017. DOI: 10.1016/j.renene.2016.09.053, [2017].

[23] M. Puchta et al., "Development and testing of a novel offshore pumped storage concept for storing energy at sea - Stensea," J. Energy Storage, vol. 14, pp. 271-275, 2017. DOI: 10.1016/j.est.2017.06.004, [2017]. 
[24] R. Atan, J. Goggins, and S. Nash, "Galway Bay - The 1/4 scale wave energy test site? A detailed wave energy resource assessment and investigation of scaling factors," Renew. Energy, vol. 119, pp. 217-234, 2018. DOI: 10.1016/j.renene.2017.11.090, [2018].

[25] R. Atan, J. Goggins, and S. Nash, "A detailed assessment of the wave energy resource at the Atlantic Marine Energy Test Site," Energies, vol. 9, no. 11, 2016.

[26] M. Previsic, R. Bedard, and G. Hagerman, “E2I EPRI Assessment Offshore Wave Energy Conversion Devices," E2I EPRI WP - $004-U S$ - Rev 1, pp. 1-52, 2004.

[27] J. Falnes and J. Hals, "Heaving buoys, point absorbers and arrays," in Philosophical Transactions of the Royal Society A: Mathematical, Physical and Engineering Sciences, 2012, vol. 370, no. 1959, pp. 246-277. DOI: 10.1098/rsta.2011.0249, [2012].

[28] A. Babarit, M. Guglielmi, and A. H. Clément, “Declutching control of a wave energy converter," Ocean Eng., vol. 36, no. 1213, pp. 1015-1024, 2009. DOI: 10.1016/j.oceaneng.2009.05.006, [2009].

[29] S. Zou, O. Abdelkhalik, R. Robinett, G. Bacelli, and D. Wilson, "Optimal control of wave energy converters," Renew. Energy, vol. 103, pp. 217-225, 2017.

[30] D. Son and R. W. Yeung, "Optimizing ocean-wave energy extraction of a dual coaxial-cylinder WEC using nonlinear model predictive control," Appl. Energy, vol. 187, pp. 746-757, 2017. DOI: 10.1016/j.apenergy.2016.11.068, [2017].

[31] T. Wang, H. Gao, and J. Qiu, "A Combined Adaptive Neural Network and Nonlinear Model Predictive Control for Multirate Networked Industrial Process Control," IEEE Trans. Neural Networks Learn. Syst., vol. 27, no. 2, pp. 416-425, 2015. DOI: 10.1109/TNNLS.2015.2411671, [2016].

[32] H. K. Khalil, Nonlinear Systems. 2015.

[33] H. Elmali and N. Olgac, "Robust output tracking control of nonlinear MIMO systems via sliding mode technique," Automatica, vol. 28, no. 1, pp. 145-151, 1992.

[34] N. Sadati and R. Ghadami, "Adaptive multi-model sliding mode control of robotic manipulators using soft computing," in Neurocomputing, 2008, vol. 71, no. 13-15, pp. 2702-2710.

[35] M. Ben Nasr and M. Chtourou, "Neural network control of nonlinear dynamic systems using hybrid algorithm," Appl. Soft Comput., vol. 24, pp. 423-431, 2014.

[36] O. Nelles, Nonlinear system identification: from classical approaches to neural networks and fuzzy models. 2001. DOI: 10.1007/978-3-662-04323-3, [2001].

[37] S. Haykin, "A comprehensive foundation," Neural Networks, vol. 2, no. 2004, p. 41, 2004. DOI: 10.1017/S0269888998214044, [2005].

[38] K. S. Narendra and K. Parthasarathy, "Identification and control of dynamical systems using neural networks," IEEE Trans. Neural Networks, vol. 1, no. 1, pp. 4-27, 1990.

[39] F. Fusco and J. V. Ringwood, "Short-term wave forecasting for real-time control of wave energy converters," IEEE Trans. Sustain. Energy, vol. 1, no. 2, pp. 99-106, 2010. DOI: 10.1109/TSTE.2010.2047414, [2010].

[40] M. Ge and E. C. Kerrigan, "Short-term ocean wave forecasting using an autoregressive moving average model," in 2016 UKACC International Conference on Control, UKACC Control 2016, 2016.

[41] J. R. Noriega and H. Wang, "A direct adaptive neural-network control for unknown nonlinear systems and Its application," IEEE Trans. Neural Networks, vol. 9, no. 1, pp. 27-34, 1998.

[42] B. P. Hayes and M. Prodanovic, "State Forecasting and Operational Planning for Distribution Network Energy Management Systems," IEEE Trans. Smart Grid, vol. 7, no. 2, pp. 1002-1011, 2016. DOI: 10.1109/TSG.2015.2489700, [2016].

[43] I. J. Leontaritis and S. A. Billings, "Input-output parametric models for non-linear systems Part I: deterministic non-linear systems," Int. J. Control, vol. 41, no. 2, pp. 303-328, 2007. DOI: 10.1080/0020718508961129, [1985].

[44] I. J. Leontaritis and S. A. Billings, "Input-output parametric models for non-linear systems Part II: stochastic non-linear systems," Int. J. Control, vol. 41, no. 2, pp. 329-344, 2007.

[45] M. Leijon et al., "Catch the wave to electricity," IEEE Power Energy Mag., vol. 7, no. 1, pp. 50-54, 2009. DOI: 10.1109/MPE.2008.930658, [2009].

[46] C. Boström et al., "Study of a wave energy converter connected to a nonlinear load," IEEE Journal of Oceanic Engineering, vol. 34, no. 2. pp. 123-127, 2009. DOI: 10.1109/JOE.2009.2015021, [2009].

[47] V. Castellucci, M. Eriksson, C. Boström, R. Waters, and Y. Hong, "Linear generator-based wave energy converter model with experimental verification and three loading strategies," IET Renew. Power Gener., vol. 10, no. 3, pp. 349-359, 2016.

[48] A. Parwal et al., "Energy management for a grid-connected wave energy park through a hybrid energy storage system," Appl. Energy, vol. 231, pp. 399-411, 2018. DOI: 10.1016/j.apenergy.2018.09.146, [2018].

[49] F. Wu, X.-P. Zhang, P. Ju, and M. J. H. Sterling, "Modelling and Control of AWS-Based Wave Energy Conversion System Integrated Into Power Grid," IEEE Trans. Power Syst., vol. 23, no. 3, pp. 1196-1204, 2008.

[50] A. J. Mahdi, W. H. Tang, and Q. H. Wu, "Derivation of a complete transfer function for a wind turbine generator system by experiments," in PEAM 2011 - Proceedings: 2011 IEEE Power Engineering and Automation Conference, 2011, vol. 1, pp. 35-38.

[51] Y. Hong, M. Eriksson, C. Boström, and R. Waters, "Impact of generator stroke length on energy production for a direct drivewave energy converter," Energies, vol. 9, no. 9, 2016.

[52] Y. Hong, Eriksson. Mikael, V. Castellucci, C. Boström, and R. Waters, "Linear generator-based wave energy converter model with experimental verification and three loading strategies," IET Renew. Power Gener., vol. 10, no. 2, pp. 349-359, 2015. DOI: 10.1049/iet-rpg.2015.0117, [2016].

[53] M. Eriksson, H. Bernhoff, K. Thorburn, and M. Leijon, "Dynamics of a linear generator for wave energy conversion," in Proceedings of the International Conference on Offshore Mechanics and Arctic Engineering - OMAE, 2004, vol. 3.

[54] M. Göteman, J. Engström, M. Eriksson, and J. Isberg, “Fast modelling of large wave energy farms using interaction distance cut-off," Energies, vol. 8, no. 12, pp. 13741-13757, 2015.

[55] J. Falnes, "A review of wave-energy extraction," Marine Structures, vol. 20, no. 4. pp. 185-201, 2007.

[56] J. Falnes, "Optimum control of oscillation of wave energy converters," Proc. Elev. Int. Offshore Polar Eng. Conf. 17-22 June 2001, Stavanger, Norway. (International Soc. Offshore Polar Eng. Cupertino, California, USA), no. June, pp. 567-574, 2001.

[57] I. Boldea and S. A. Nasar, "Linear electric actuators and generators," IEEE Trans. Energy Convers., vol. 14, no. 3, pp. 712 717,1999

[58] S. Chent, S. A. Billingst, and P. M. Grantt, "Non-linear system identification using neural networks," INT. J. Control, vol. 51, no. 6, pp. 1191-1214, 1990.

[59] D. Wang and P. Bao, "Enhancing the estimation of plant Jacobian for adaptive neural inverse control," Neurocomputing, 2000. DOI: 10.1016/S0925-2312(00)00319-2, [2000].

[60] R. Kumar, S. Srivastava, and J. R. P. Gupta, “Comparative Study of Neural Networks for Control of Nonlinear Dynamical Systems with Lyapunov Stability-Based Adaptive Learning Rates," Arab. J. Sci. Eng., vol. 43, no. 6, pp. 2971-2993, Jun. 2018. 